\title{
A ALDEIA E O URBANO NO CONTEXTO DA GLOBALIZAÇÃO:
} QUESTIONAMENTOS E REFLEXÕES

\section{THE INDIGENOUS VILLAGE AND THE URBAN IN THE GLOBALIZATION CONTEXT: QUESTIONS AND REFLECTIONS}

\author{
Evaristo Giovannetti Netto ${ }^{1}$ \\ Waldir José Gaspar ${ }^{2}$ \\ Morane Almeida de Oliveira ${ }^{3}$
}

\section{RESUMO}

Este artigo pretende discutir as mazelas causadas pela pós-modernidade alimentadas pela globalização e a dominação do sistema capitalista dentro do contexto das minorias inseridas nas cidades, em especial aos indígenas. $\mathrm{O}$ foco da pesquisa priorizou contextualizar a identidade e liberdade dos indígenas e compreender a intensidade das interações humanas na realidade das esferas sociais, econômicas e políticas. Dentre outros autores, como linha mestra para o embasamento teórico, foram analisadas as premissas sobre o liberalismo e liberdade humana contidos nos estudos de Weber (1974), a identidade coletiva comentada em Sennett (1988), a vulnerabilidade da população em Safatle (2015), a desigualdade social de Piketty (2015) e os aspectos da diferença cultural nos estudos de Bauman (1998 e 2013). Conclui-se, nesta investigação que o momento histórico do qual pertencemos, configura-se fluido e tenso, que tendências opostas à individualidade e à globalidade se manifestam na dimensão local, e os atores engajados a estas novas interpretações, anseiam por estabelecer um novo corpus teórico capaz de instrumentalizar novas pesquisas e análises.

Palavras chave: Minorias, pós-modernidade, urbanidade moral, grupos socioculturais.

\begin{abstract}
This article intends to discuss the ills caused by postmodernity fueled by globalization and the domination of the capitalist system within the context of minorities inserted in the cities, especially indigenous peoples. This research focused on prioritizing the decrease of indigenous identity and freedom, as well as on understanding the intentionalities of human interventions in the reality of social, economic and political spheres. Among other authors, as a guideline for the theoretical basis, we analyzed the premises about liberalism and human freedom contained in the studies of Weber (1974), the collective identity commented in Sennett (1988), the vulnerability of the population in Safatle (2015), Piketty's (2015) and also the social inequality and aspects of cultural difference in Bauman's (1998 and 2013) studies. It is concluded from this investigation that the historical moment to which we belong is fluid and tense, that tendencies which are opposed to individuality and globality manifest themselves in the local dimension, and the actors engaged in these new interpretations yearn to establish a new theoretical corpus which is able to instrumentalize new research and analysis.
\end{abstract}

Keywords: Minorities, postmodernity, moral urbanity, sociocultural groups.

1 Doutor em História Social pela Pontifícia Universidade Católica de São Paulo. E-mail: egiovanettinetto@gmail.com

${ }^{2}$ Doutor em Ecologia e Recursos Naturais pela UFSCar. Professor do Centro Universitário Belas Artes de São Paulo e do PPGECEM - REAMEC. E-mail: gasparhome@terra.com.br

3 Mestre em Ensino de Ciências e Matemática pela UFAC. Doutorando do PPGECEM. E-mail: morane.oliveira@ifac.edu.br 


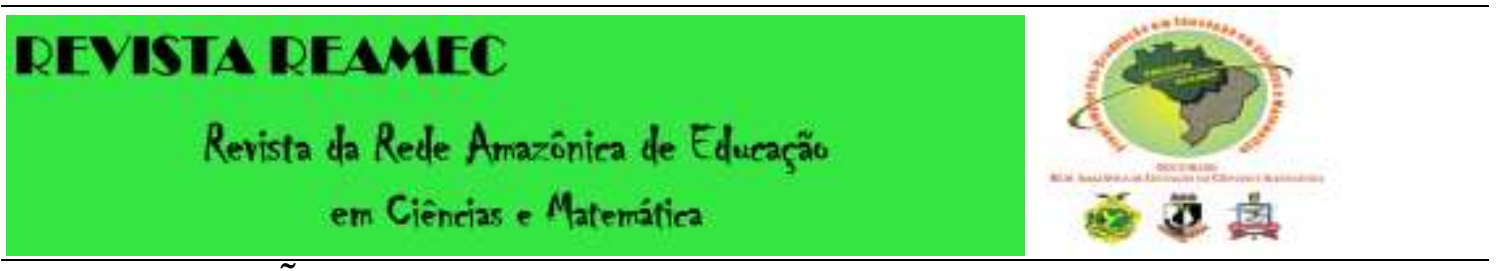

\section{INTRODUÇÃ̃O}

Não o florescer do verão está à nossa frente, mas antes uma noite polar, de escuridão gelada e dureza, não importa que grupo possa triunfar externamente agora (WEBER, 1974, p. 152).

Ao longo das reflexões buscou-se problematizar as contradições implicadas pela globalização e a dominação do sistema capitalista e seus interesses, ressalvando as minorias inseridas nos centros urbanos, em especial a luta desenvolvida pelos indígenas buscando garantir sua sobrevivência mantendo sua identidade.

Os conceitos não são refratários ao modo constante e, por vezes até inquietante, com que a realidade se reconfigura. Cidadania, urbanidade, povos tradicionais, cultura e aculturação, enquanto conceitos operacionais, desafiam nossa capacidade de pensar a diversidade do mundo. Neles está contida e a dinâmica das relações que se travam na vida cotidiana, com todas as suas contradições, explicitadas pelas ações dos homens que, pela sua própria natureza - já dizia Aristóteles - é um animal político destinado a viver com os outros no âmbito da polis, onde espaço e movimento prefiguram a realidade material e cultural em que estão imersos por inteiro na luta pela sobrevivência.

O dinheiro, cuja essência é o cálculo, entendido aqui como um ato da vida cotidiana, mensura o valor das coisas, tendo como produto o trabalho e, por extensão das pessoas. Se por um lado as trocas trazem alguma precisão ao envolvimento, por outro, estabelece uma cisão na medida em que a racionalidade que dá origem na interação entre os homens, não corresponde às relações que os mesmos estabelecem com o poder público. Tanto uma como outra se enredam de forma complexa não sem deixar em plano inferior as experiências afetivas que travam entre si, permeadas pela individualidade.

Defrontamo-nos então com a dinâmica instável e a volatilidade de valores da vida, com as contradições mais ou menos agudas em relação às quais cada indivíduo e cada segmento da sociedade reage. Reação em diversos graus e variadas maneiras e de forma subjetiva, conforme os fenômenos que o atingem (o indivíduo) nos marcos da economia, da política, da cultura e das heranças transmitidas pelas gerações.

Sob o ponto de vista da economia, fornecedores e clientes ou consumidores que se desconhecem se defrontam no âmbito do mercado travando uma relação impessoal; no âmbito da política, verifica-se que o exercício dos direitos e deveres se explicitam de modo bastante injusto e desigual; por fim, mas não por último, a que se destacar o 


\section{REVISTA REAMEC}

Revista da Rede Amazônica de Edureaçäo

em Ciências e Matemática

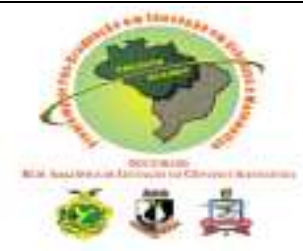

sentimento de pertença a alguns valores do lugar ou do grupo que ocorre no mundo da cultura e que define o espaço de cada um, dimensionando sua parcela de liberdade e poder real que exercem.

Não se pode deixar de considerar as realidades objetivas e subjetivas, racionais ou emocionais que alimentam o ódio e a paixão pela cidade, aldeia ou lugar e também a indiferença suscitada na medida em que somos engolfados pela realidade e pela rede de leis.

As referidas leis, a pretexto de reger nossas vidas, emprestam-lhes alguma previsibilidade, mas por outro lado, aquelas que descumprem a promessa de felicidade que a proximidade da vida urbana parecia prometer, subitamente encoberta a permanente tensão e a brutalização que a desregulamentação que acompanha a globalização da economia e o desmanche e substituição do estado de bem-estar social por políticas compensatórias por vezes de caráter meramente populista.

As políticas implementadas, de forte viés neoliberal, mal encobrem o caráter destrutivo e desumanizador das relações de trabalho no interior do sistema capitalista e a sujeição a que ficamos todos submetidos. Essa submissão, em maior ou menor grau, afeta principalmente as classes subalternas e os grupos minoritários devido à servidão a que estão sujeitos nas rodas dentadas da produção, tanto nas malhas do Estado quanto das grandes corporações, além do modo como se tem imprimido unidade à conduta e impedido a dispersão em nome da racionalidade exigida pelo sistema econômico.

É com o tempo, essa matéria fautora da História, a despeito de sua natureza poética, vaga e fluída, como de resto é a própria existência, que produzimos e consumimos nas mais diferentes condições, as coisas e bens de que carecemos para atender às nossas necessidades - via trabalho.

Observa-se que, seja qual for o regime político e o sistema econômico em que se realiza, o trabalho é um componente orgânico, tendo como prova os dispositivos disciplinares que cercam as relações de propriedade, seja do Estado ou de uma classe, tanto numa economia planificada e centralizada ou economia liberal e capitalista de livre mercado, se considerarmos a tendência dos governos de regular as atividades econômicas em função dos interesses do Estado, ainda que em detrimento da liberdade.

Tanto num caso como no outro, não é difícil dimensionar a que fica reduzida a identidade e a liberdade de pessoas e grupos minoritários e o modo como são 


\section{REVISTA REAMEC}

Revista da Rede Amazônica de Eduração

em Ciências e Matemática

$\overline{\text { reconhecidos como partes do todo e seu próprio direito à vida que se pode avaliar }}$ mediante o grau de liberdade e reconhecimento de que dispõem. No que concerne à identidade, a questão levantada por Richard Sennett consiste em "saber como se formam esses retratos de identidade coletiva e quais são os instrumentos que as pessoas usam para forjar um sentido de quem somos "nós"” (SENNETT, 1988, p. 275, grifo do autor).

No que diz respeito à liberdade Max Weber (1974) comenta que, em 1906, a possibilidade da liberdade e da democracia sob o domínio de um capitalismo altamente desenvolvido era questionável. No prefácio da obra de Weber (1974), Hans Gerth e Wright Mills, comentam que a preocupação de Weber com a liberdade, “...não foi apenas histórica influenciando sua imagem de homem contemporâneo como indivíduo...”, e complementam dizendo que a liberdade está correlacionada “...como um composto de características gerais, derivadas das instituições sociais, ou seja, o indivíduo como um ator de papéis sociais”. (WEBER, 1974, p. 92-93)

Os mesmos autores notam que a concepção weberiana de liberdade humana se filiava à tradição humanista do liberalismo, interessada pela liberdade do indivíduo como criador de instituições livres, incorporando também a crítica marxista do capitalismo na medida em que percebia o sistema econômico como um aparato compulsivo mais que como sede da liberdade. Entende-se que Weber representa o liberalismo humanista e cultural em preferência ao liberalismo econômico quando apresenta que:

O capitalismo é a materialização da impessoalidade racional; a busca da liberdade identifica-se com o sentido racional e os aspectos privados. Nessa concepção de liberdade como um fenômeno desenvolvido historicamente, hoje na defensiva contra o capitalismo e a burocracia (WEBER, 1974, p. 93).

O declínio do humanista e a ascensão do perito, constituem para Weber, outra prova de menores oportunidades de liberdade. Fato é que as promessas da democracia liberal, assim como as promessas dos sistemas totalitários, tanto sob a forma do nazifascismo como da experiência do socialismo, tal como foi entendido e praticado, jamais evitaram as distorções.

As violações de direitos fundamentais e os crimes perpetrados contra a vida, todas as vezes que seus fautores tiveram a oportunidade de colocar em prática suas teorias e ideias e deixaram que seus ideais fossem contaminados nas nervuras obscuras do poder, a ponto de engendrar, no caso da democracia, uma elite política profissional, empresarial 


\section{REVISTA REAMEC}

Revista da Rede Amazônica de Eduração

em Ciências e Matemática

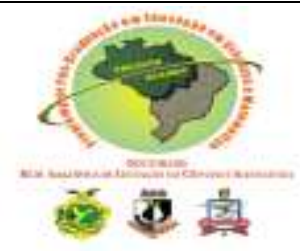

e corrupta e, nos demais casos, uma burocracia pérfida que procurou invadir todas as esferas da vida sem jamais levar em consideração a natureza da condição humana.

Ambos os sistemas de organização política e econômica demonstram, de forma cabal, o deletério poder de radicalizar as posições e inocular a perfídia nas relações entre as pessoas e grupos, além de estimular mecanismos de cooptação e rejeição, tanto pelo excesso de zelo e abuso de autoridade do aparato policial, menos a serviço da população do que do Estado ou pelo oferecimento de vantagens nos seus interstícios do seu aparelho burocrático.

\section{ENTRE O GLOBAL E O LOCAL}

O conhecimento só é capaz de proporcionar um alargamento se ele adere ao indivíduo com uma tal insistência que seu isolamento se desfaz (ADORNO, 1993, p. 64).

A esta altura ninguém pode assegurar que aqueles que hoje apostam nas promessas do neoliberalismo e do livre mercado, não venham experimentar depois de amanhã, a mesma desilusão daqueles que apostaram nas promessas do socialismo depois da derrocada do Império Soviético. Cioran (2014, p.43) adverte contra o risco de construir nossa vida sobre certezas, posto que não as temos e não devemos ser tão covardes a ponto de inventar certezas estáveis e definitivas.

É deveras importante reconhecer que no contato com a realidade, as ideias se tornam impuras e a intervenção humana, na medida em que se insere nos desdobramentos da vida econômica, social e política, cria uma cisão que divide a sociedade entre limpos e sujos, os que fazem parte dela e os que foram excluídos e, neste caso, jamais se pode garantir que os primeiros sejam íntegros (a julgar pelos que supostamente nos representam nas casas legislativas ou pelos que tem assento nos tribunais) e que os últimos sejam todos não-confiáveis.

Mais que frequente é a tendência de imputar a alguns as mazelas que dificultam a urdidura de uma sociedade mais harmoniosa, justa e solidária e de um ambiente mais propício para uma vida em que a boa ordem possa existir sem prejuízo da liberdade e do direito inalienável de todos na busca da felicidade e bem-estar.

Os alvos preferenciais sobre os quais recai a desconfiança são geralmente aqueles que estão presentes nas mais diferentes situações da vida cotidiana, tanto no mundo do 


\section{REVISTA REAMEC}

Revista da Rede Amazônica de Edureaçäo

em Ciências e Matemática

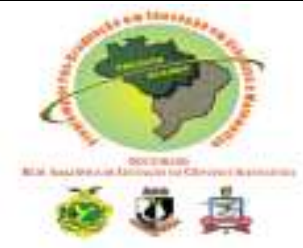

trabalho quanto no tempo ocioso. Esses grupos, desprovidos de poder, são obrigados a fazer malabarismos para sobreviver e escapar das armadilhas ardilosas a que ficam expostos sempre que procuram se unir e organizar para defender seu lugar, seu território e sua identidade cultural apesar da falta de recursos e do risco que correm em função da discriminação social e/ou racial. Dentre estes, com essas peculiaridades, se encontram os grupos indígenas.

É moralmente indefensável cultivar e reproduzir esses sentimentos contra aqueles que são os protagonistas da história e é espantoso que tanto a direita quanto grupos da esquerda postulam políticas cujo objetivo é mantê-los à parte ou quando muito desenvolver políticas de caráter meramente assistencialista cujo objetivo está longe de incluí-los ou ações paternalistas de resultado pífio que jamais consideram o caráter destrutivo das suas relações. Observa-se, tanto no interior do sistema capitalista quanto na alternativa à esquerda que a ele se opõe, a existência da corrosão do ethos dessas comunidades. Na concepção de Lipovetsky e Serroy (2011):

Em um universo livre de referências coletivas o hipercapitalismo faz crescer a insegurança tanto social quanto individual; ele não acarreta apenas uma instabilidade macrofinanceira, mas também desestabiliza as personalidades e as identidades, desequilibra a vida mental e moral dos indivíduos tornados inseguros e que já não dispõem de apoio dos antigos quadros da vida coletiva (LIPOVETSKY; SERROY, 2011, p. $37)$.

Diante da falência das utopias e modelos e da instabilidade e imprevisibilidade da vida parece que as ideias claudicam, não logram articular respostas para os desafios contemporâneos e ficamos expostos ao presente e à verdadeira e insidiosa fúria dos legisladores a que - na carência aguda de estadistas e de homens de espírito público - os políticos acorrem de modo improvisado e oportunista.

É de se lamentar que os parlamentos, em todos os níveis, estejam cada vez mais empenhados em criar leis que buscam controlar cada vez mais as atividades cotidianas dos cidadãos, intervindo até em questões que sempre estiveram e deveriam estar fora de seu âmbito e alheias às suas atribuições. Muito mais desejável seria afirmar o princípio de que é melhor recorrer às forças responsáveis da sociedade do que apelar para leis, interditos e coações que geralmente constrangem mais do que educam.

As interferências do poder que se supõe público e representativo para regular a vida, aparar e mediar conflitos, arrasta consigo um ímpeto regulatório que a pretexto de 


\section{REVISTA REAMEC}

Revista da Rede Amazônica de Eduração

em Ciências e Matemática.

proteger segmentos mais vulneráveis, acaba invadindo todas as áreas. Vladimir Safatle adverte que a regulação disciplinar da vida avança sempre que a estrutura jurídica fortalece sua presença, mesmo quando o faz na defesa de setores mais vulneráveis da população (SAFATLE, 2015, p. 360).

Os detentores do poder (nem sempre muito visíveis) ou das rédeas temporárias do governo estão menos preocupados com os problemas reais do que com o desejo de transformar o domínio que detém na economia em poder político e, para isso asseguram pelo poder do dinheiro, a formação de bancadas legislativas dóceis e subservientes aos seus desígnios, além de assegurarem posições estratégicas nas estruturas decisórias da burocracia estatal. Prova disso é o perdão periódico das dívidas de grandes proprietários rurais, que são os maiores colaboradores do desmatamento, a liberação do uso de indiscriminado de agrotóxicos, a leniência com a evasão de tributos, o parcelamento periódico das dívidas tributárias, os empréstimos agrícolas e industriais a juros subsidiados, o recurso costumeiro à violência policial, cuja eficiência deveria ser medida pelos crimes e delitos que coíbe e pelo grau de proteção que oferece aos cidadãos, incluindo grupos étnicos, mais do que pelo número de pessoas que mata.

Sob a luz desse quadro onde essa realidade se revela de maneira mais crua, se observa a cidade como potencial lar de pequenos grupos identitários, encurralados pelo cinturão da expansão agropecuária ou das cidades, dentre eles, centenas de indígenas, como personagens que se mostram na medida em que por ela circulam e dela se apossam buscando uma experiência. Tudo o que acontece, cada ato e cada fato arrastam consigo um devir que reconfigura sua realidade agora urbana e desencadeia um processo dinâmico, silencioso algumas vezes e ruidoso outras, que pode engendrar novas formas de vida e de sociedade ao mesmo tempo em que suscita resistências.

Essa realidade exige um novo corpus teórico capaz de, a partir de novos conceitos ou conceitos repensados e adequados para operacionalizar novas pesquisas e análises, novas interpretações, pois da mesma forma que a imagem do homem se deforma diante do espelho, a ponto dele sequer se reconhecer, a realidade contemporânea se revela sempre mais instável e cambiante.

Assim, as teorias dos e sobre os indígenas bem como os conceitos se ajustam na medida em que no embate dialético com a realidade que procuram compreender e explicar se autocorrigem, delimitando um tempo que tende a ser cada vez mais reduzido em face 


\section{REVISTA REAMEC}

Revista da Rede Amazônica de Edureaçäo

em Ciências e Matemática

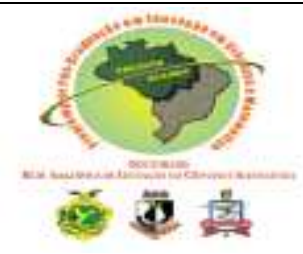

das rápidas transformações pelas quais o mundo passa. A busca de respostas para o drama vivido pelas áreas urbanas em particular e pelas sociedades em que estão inseridas pressupõe explicitar as perguntas capazes de clarear a imagem turva, preocupante e desafiadora.

Terá o indígena, supostamente que trocar sua possibilidade de felicidade e liberdade pela necessidade de segurança e autopreservação? Terá o indígena, em face da crescente vulnerabilidade a que está exposto, aceitar o sacrifício parcial de sua liberdade pela segurança ou é a segurança, no seu sentido mais amplo, que deve assegurar a liberdade?

Em que medida a resignação pela redução da liberdade e das garantias individuais se inscreve numa pauta ou reação conservadora que aspira por restrições sempre maiores e interferências invasivas na vida privada e no comportamento das pessoas? E também em que medida a busca da felicidade individual pode se sobrepor ao bem-estar de todos e a uma felicidade compartilhada?

E mais, deveria um grupo fazer de sua identidade cultural uma armadura defensiva e uma trincheira refratária ao contato e convivência com os outros grupos?

Bauman (2013, p. 64) destaca que "a universalidade da espécie humana não se opõe à pluralidade das formas de vida humana". Isto posto, é possível afirmar que a potencialidade de uma cultura particular não pode ser jamais considerada se não for testada nos marcos da diversidade e do encontro ou confronto com a alteridade; abrir-se às experiências do outro sem que seja necessário abdicar de sua singularidade é essencial.

Não se trata jamais de um respeito travestido de tolerância que a todos atraiçoa sob disfarces e gestos dissimulados. Assim, as demandas por reconhecimento e afirmação da cultura de um grupo étnico ou religioso, por exemplo, é mais que justa como também deve ser o desejo desses mesmos grupos de se incorporar ao conjunto da sociedade sem deixar de ser o que são. Ressalve-se, entretanto que o louvável esforço por inclusão social e respeito à alteridade não precisa e nem deve abdicar dos valores que prezamos - livre arbítrio e individualidade.

Vale o mesmo para todos aqueles que desejam ver respeitadas suas condições de gênero, suas preferências ou opções sexuais e confissões religiosas (ou a falta delas) bem como suas ideias e concepções de sociedade. Ressalve-se, entretanto que essas demandas particulares ou específicas de cada grupo não precisam elidir as questões mais amplas que 


\section{REVISTA REAMEC}

Revista da Rede Amazônica de Edureaçäo

em Ciências e Matemática

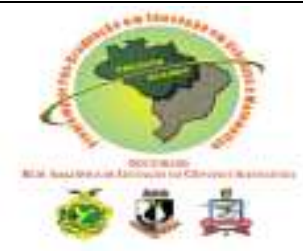

abarcam o todo e a todos dizem respeito. O contrário disso significa urdir uma sociedade sob o signo da ignorância, na qual o primeiro mandamento seria odiar o próximo e o diferente como inimigo e amar a si próprio e a seus iguais sobre todas as coisas; uma sociedade que mais se aproximaria do desmanche, um dilaceramento cujo tecido se esgarça quanto mais o remendamos, elevando à enésima potência o egocentrismo.

Não se pode omitir que as ameaças que pairam sobre a sociedade e, particularmente, sobre a vida urbana - sempre em prejuízo da civilidade, da liberdade e da segurança - estão fortemente vinculadas à desigualdade que o processo de globalização estreitamente vinculado ao neoliberalismo não logrou atenuar senão acentuar.

Ribeiro (2015, p.131) sintetiza esse pensamento apresentando que "[...] fica sempre mais exposto aos olhos de todos a vulnerabilidade daqueles grupos que atravessam os limites das cidades e as assediam, a ninguendade." O sem-lugar, os sem espaço, os invisíveis e aqueles cujos vínculos com a sociedade de onde vieram e da sociedade que pretendem chegar foram no todo ou em parte rompidos.

Piketty (2015) verifica que a questão da desigualdade está no centro dos conflitos políticos opondo a direita liberal e a esquerda tradicional. A primeira, no seu entender, aposta nas forças de mercado, na iniciativa privada individual e no aumento da produtividade como meio de favorecer a longo prazo uma melhora efetiva de renda dos mais desfavorecidos. A segunda, aposta nas lutas sociais e políticas capazes de atenuar a miséria que no seu modo de ver fora produzida pelo sistema capitalista. Segundo o autor:

\footnotetext{
"O verdadeiro conflito ocorre com frequência muito maior em relação à maneira mais eficaz de melhorar as condições de vida dos mais pobres e à extensão dos direitos que podem ser concedidos a todos do que em relação aos princípios abstratos de justiça social.” E prossegue: “[...] só uma análise minuciosa dos mecanismos socioeconômicos que produzem a desigualdade é capaz de definir a parcela de verdade dessas duas visões extremas da redistribuição e talvez contribuir para a instauração de uma redistribuição mais justa e eficiente." (PIKETTY, 2015, p. 9-10.)
}

Disto resulta que, em face da desigualdade persistente e crescente, que o capitalismo e o socialismo (particularmente em sua versão soviética), revelam algo em comum: não lograram jamais exibir um olhar obsequioso e humano. 


\section{REVISTA REAMFC}

Revista da Rede Amazônica de Edureaçäo

em Ciências e Matemática

Dentro desse quadro no qual se acentua o caráter destrutivo que a desigualdade que os anos de desregulamentação e desmantelamento do Estado de bem-estar social, só fez aumentar, a democracia tem revelado certa impotência e paralisia que já fora prevista por Max Weber no início do século XX.

Nos marcos de uma sociedade desigual, a desconstrução das diferenças culturais pelo apelo à tolerância e "a ilusão tipicamente liberal de um pluralismo sem antagonismo" a que se refere Mouffe (1995, p. 39) não tem se mostrado capaz de afastar o risco de conflitos extremamente regressivos, alimentados pelo ressentimento e pelo preconceito, favorecidos por falaciosas políticas de tolerância que não trazem nenhuma força transformadora, nenhuma promessa substantiva.

Corroborando com o autor acima mencionado, Safatle (2015, p.130) alerta: "Diante das promessas de gozo produzidas pela sociedade capitalista em ascensão, toda satisfação limitada é insuportável exatamente por ser uma limitação, toda escolha identitária é sem sentido porque guarda em si uma multidão de recusas".

Mas estará a sociedade como um todo disposta a apoiar políticas redistributivas ou programas para sanar as demandas sociais e dos povos minoritários, em especial os indígenas, financiados pelos impostos? E, como o mercado reagiria ao intervencionismo do Estado no sentido de regular os lucros apropriados pelos detentores do capital ou no sentido de estabelecer exigências que oneram as folhas de pagamento em plena época de desregulamentação?

Se de um lado as discrepâncias acima mencionadas são moralmente indefensáveis, por outro não se tem nenhuma garantia de que a intervenção de um Estado provedor e planificador não apresentem implicações e efeitos colaterais indesejáveis. Para Richard Sennett, não resta dúvida de que:

[...] se quisermos assegurar uma distribuição da riqueza segundo um padrão predeterminado, se quisermos estabelecer conscientemente o que caberá a cada um, teremos que planificar todo o sistema econômico. Resta saber se o preço que teremos que pagar pela realização desse ideal de justiça não seria um descontentamento e uma opressão maiores do que as jamais causadas pelo livre jogo das forças econômicas, alvo de tão severas críticas (SENNETT, 1988, p. 132).

Seria preciso indagar que mecanismos de redução da desigualdade com apoio a etnias minoritárias e redistribuição de renda se poderia estender à segmentos cada vez mais amplos da população de modo que se mostre a nossos olhos inquietos ou, por vezes, 


\section{REVISTA REAMEC}

Revista da Rede Amazônica de Edureaçäo

em Ciências e Matemática

indiferentes, sem explicitar de modo tão constrangedor nas cenas do cotidiano a magnitude e a insanidade dessas disparidades.

É crível que o livre-mercado desembaraçado de qualquer regulação ofereça perspectivas para mudar essa realidade no quadro atual? Entende-se que, apoiando-se nas práticas viciadas e nos surtos autoritários da política contemporânea, cujos métodos implicam em afastar sempre mais suas elites dos trabalhadores que buscam efetiva representação, não permitem conduzir a uma resposta afirmativa.

Em que medida se pode apostar em políticas intervencionistas do Estado mediante mecanismos compensatórios de modo a assegurar uma melhoria permanente na condição de vida dos grupos indígenas e de uma sociedade excludente, assegurando sua superação das contradições e sobrevivência?

Voltando o olhar para o poder público, não é possível afirmar que os complexos problemas que atingem os centros urbanos encontrem ressonância nas modorrentas câmaras municipais onde o interesse privado prevalece sobre o interesse público ou das minorias.

O conhecimento que se produz da vida urbana extrapola, por certo, a ocupação do território, as edificações, a circulação dos bens materiais e culturais e o modo como seus habitantes interagem, posto que deve incorporar também os processos culturais e os imaginários e tensões dos que a habitam e por ela circulam. Na mesma intensidade que a ideia de cidade habita o coração e a mentalidade dos homens com seus sonhos, esperanças e frustrações, que a realidade sempre reluta em oferecer o que a imaginação promete e a esperança cultiva. Sob esse aspecto Canclini (2008), observa que:

O imaginário não é apenas a representação simbólica do que ocorre, mas também um lugar de elaboração de insatisfações, desejos e busca de comunicação com os outros. Os desequilíbrios e incertezas engendrados pela urbanização que desurbaniza por sua expansão irracional e especulativa parecem compensados pela eficácia tecnológica das redes comunicacionais (CANCLINI, 2008, p. 21).

Não se pode pretender por certo, que a análise que se faz nos marcos do atual aparato teórico-metodológico e conceptual, possa abranger e filtrar a totalidade dos processos das concepções de vida e do imaginário a que dá origem sem considerar o modo como a vida e a experiência da vida são atravessadas por formas de convivência fundadas no reconhecimento, na coexistência, nem sempre isenta de conflitos e no intercâmbio, 


\section{REVISTA REAMEC}

Revista da Rede Amazônica de Edureaçä

em Ciências e Matemática

além do modo como as relações são permeadas pelos fluxos globais da economia que passam ao largo de modelos homogeneizadores.

Cada cultura, a partir da experiência concreta cria seus padrões de convivência, em função dos quais se desenvolve seus conceitos de civilidade, padrões que, atualmente não são refratários às transformações que, em grau maior ou menor atingem os homens e mulheres de todas as idades e condições.

No caso de sociedades cuja convivência e sociabilidade são agravadas por grandes distorções de ordem econômica, os que ficam "de fora" sofrem o estigma da exclusão, encontram modos de se organizar e modelam suas vidas, produzindo imagens da aldeia, da cidade e da marginalidade. Tais redutos, muitas vezes da violência e de formas alternativas de navegação social à margem do poder público asseguram sua sobrevivência e não escapam sequer ao olhar curioso dos turistas, inscrevendo-se na paisagem muitas vezes de forma agressiva turvando o ambiente, criando um clima de desconfiança de todos contra todos e pondo à prova os valores de vida.

Recrudesce então a violência sob as mais variadas formas, colocando em risco o patrimônio e a vida numa guerra travada no espaço privado, de que é prova a desintegração da vida familiar e, no espaço público, e também a batalha travada nas ruas. Soma-se a isso o despreparo e descontrole do aparato policial do Estado, cujo braço armado incide com maior força e arbítrio sobre os mais pobres e desassistidos, sem olvidar insidiosas políticas alimentadas por um discurso que discrimina e segrega alimentando a animosidade entre grupos, classes e raças, não obstante camuflado sob a ideologia da tolerância.

Safatle (2015) observa então com a argúcia característica do seu texto aqui já mencionado que:

Uma política baseada na tolerância é uma política que constrói um campo de diferenças toleráveis, o que alimenta o fantasma perpétuo da "diferença intolerável", ou seja, a equação das diferenças, tão presente nas dinâmicas multiculturais parte da seguinte questão: até onde podemos suportar uma diferença? Essa é, no entanto, uma péssima questão. Parte-se do pressuposto de que vejo o outro primeiro a partir da sua diferença em relação à minha identidade. Como se minha identidade já estivesse definida e simplesmente se comparasse à identidade do outro. Por isso, a boa questão talvez seja: em que condições a diversidade pode aparecer como a modulação de uma mesma universalidade em processo tenso de efetivação? Isso implica não compreender o campo político como campo de identificação e 


\section{REVISTA REAMEC}

Revista da Rede Amazônica de Edureaçäo

em Ciências e Matemática

reconhecimento das diferenças, mas como campo de desconstrução das diferenças (SAFATLE, 2015, p. 350, grifos do autor).

O pior que pode acontecer - e assim tem sido - é estabelecer interditos e zonas de exclusão, é desenvolver esforços para afastar o outro, o estranho, o diferente, cercandose de reservas e de proteção numa paranoia de medo e segurança em face das diferenças e da criminalidade que, ressalta Bauman (1998) “[...] a desregulamentação e a deliberada destruição das garantias do sistema de bem-estar só contribuiu para aumentar." (BAUMAN, 1998, 58).

Paga-se hoje, um desmesurado preço por uma política de exclusão fundada na obsessão e no temor que passa a impregnar a cotidianidade, alimentando idiossincrasias e liberando os mais baixos instintos da natureza humana. A realidade tem mostrado e explicitado em imagens e manchetes a dificuldade de construir ou afirmar uma identidade numa sociedade que se volta para a constituição da ordem. As ruas das cidades têm sido testemunhas de explosões de ira e revolta que deixam vestígios de sangue nas calçadas, de modo a desmentir a ideia de um mundo cada vez mais homogêneo em face da crua realidade em que as diferenças e as desigualdades se revelam.

Observa-se que tanto a luta por acesso a políticas públicas efetivas em Terras Indígenas quanto as reformas urbanas que foram levadas a cabo por urbanistas, foram feitas para separar mais que unir, afastar mais que aproximar, fenômeno que se reproduziu em todos os âmbitos e que nenhuma intervenção política logrou reverter. Em vista disto, Sennett (1988) adverte:

Os planificadores urbanos ainda precisam aprender uma profunda verdade que os escritores conservadores já perceberam, embora fizessem mau uso dela: as pessoas somente podem ser sociáveis quando dispõem de alguma proteção mútua; sem barreiras, sem limitações, sem a distância mútua que constituí a essência da impessoalidade, as pessoas são destrutivas. E é assim, não porque a natureza do homem seja malévola, este é o erro dos conservadores, mais porque o efeito último da cultura gerada pelo capitalismo e pelo secularismo moderno torna lógico o fratricídio, quando as pessoas utilizam as relações intimistas como base para as relações sociais (SENNETT, 1988, p. 379).

O Estado acabou por conformar uma ordem que, a serviço de múltiplos interesses, separou uns e outros sob os mais variados pretextos para que ele possa prevalecer e impor seus projetos, quase sempre em benefício de poucos e prejuízo de muitos, não obstante 


\section{REVISTA REAMEC}

Revista da Rede Amazônica de Edureaçäo

em Ciências e Matemática

cultive a imagem de um poder público provedor de toda a população e garantidor da funcionalidade do sistema urbano.

Revelam-se então as contradições que tornam evidentes a fragilidade da ideologia da cidade que é de todos e de um poder público (apenas no nome), refém de poderosos interesses que encontram sempre acolhida nos meandros legislativos municipais como também em outros níveis da administração e da burocracia.

O mesmo "poder" que se propõe assegurar as condições dignas de vida para o conjunto da população marginalizada, se vê na contingência de garantir o uso desenfreado do solo baseado na propriedade privada, o "poder" que precisa manter as condições de funcionamento da cidade, enfrenta a carência ou o mau uso de recursos; o "poder" que, sob a pressão de fortes interesses precisa manter o caráter impositivo da concentração espacial das atividades produtivas de um lado, precisa por outro lado, assegurar o controle e coerção da população. Trocando em miúdos, o fato de se apresentar como "de todos", não consegue ocultar a contradição entre a imagem que cultiva e projeta através da propaganda institucional e os limites de sua capacidade de atender a todas as demandas.

Compreende-se então que a propaganda enganosa e ações imediatistas deixam em plano bem inferior a elaboração e execução de planos capazes de pensar a sociedade em que está inserida como um todo e, a médio e longo prazo, planos que não podem se ater apenas ao período de uma administração e que a propaganda partidária do período eleitoral tangencia e mascara. Tanto mais preocupante é o fato bem assinalado por Augé (2010), segundo o qual “[...] os políticos parecem hoje desarmados, carentes de ideias e de modelos. Eles se refugiam na gestão do presente, a 'governança'”. (AUGÉ, 2010, p. 11, grifo do autor).

Nesse quadro, era inevitável que a emergência de movimentos sociais que, no embate com o poder público passaram a politizar os conflitos, segmentar as demandas e a colocar em discussão a necessidade de introduzir suas críticas e reivindicações no aparato administrativo.

Cabe ressaltar que os movimentos a que se acaba de fazer referência, defrontamse, por sua vez, com a necessidade de romper o isolamento e se mobilizar em função de um projeto histórico mais amplo do que em função apenas de interesses particularistas e corporativos. 


\section{REVISTA REAMEC}

Revista da Rede Amazônica de Edureaçäo

em Ciências e Matemática

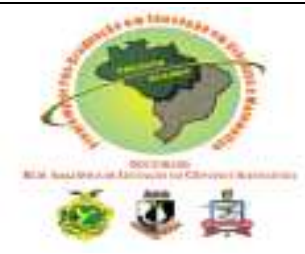

Agora, nos marcos da pós-modernidade e de um processo de globalização que já começa a apresentar fissuras, quando se optou pelo consumismo e pelo incentivo ao mais exacerbado individualismo, em detrimento de outros valores menos permeados pelas exigências do mercado, a incerteza e a insegurança, casadas com uma mútua desconfiança, encontram solo propício, a ponto da sociedade se ver ameaçada pelo estranhamento e pela brutalização.

Ninguém é poupado e, em grau maior ou menor, a insegurança e a imprevisibilidade a todos espreitam na medida em que se volatilizam os empregos e a seguridade social. Prova inelutável disso é a arquitetura do medo, da exclusão e da intimidação que demarca os espaços em nome da proteção e da vigilância configurando um verdadeiro ainda que dissimulado apartheid.

Em escalas diferentes o que se observa são ações etnocidas e genocidas no que concerne às minorias indígenas e, pelas ruas das cidades, a ubiquidade da crise da qual as manchetes dos jornais, os índices das bolsas de valores, as taxas de inflação e os clamores da mídia constituem apenas a ponta de um iceberg a denunciar o perigo que a todos espreita.

A luta por um lugar para chamar de seu e pela subsistência, não se esgota no plano da economia, mas arrasta consigo a imprevisibilidade e tira de uma zona que se imaginara esquecida ou em parte superada, os mais atávicos e abjetos instintos que assumem a forma de racismo, de aversão declarada ou encoberta pelo outro, pelo diferente, da violência contra a mulher, da homofobia, da perda de referências e valores, da violência cotidiana e da imprevisibilidade do terror.

As pessoas subitamente descobrem-se desprotegidas, percebem que estão muito próximas umas das outras, mas não estão juntas e que se tornaram extremamente vulneráveis e objeto de experiências tresloucadas de governantes - à esquerda e à direita - nos quais não confiam e de partidos políticos que, perdidas a substância e a credibilidade não são mais que legendas espúrias que expõem sua nudez no mercado eleitoral, como a nos certificar que todas as bandeiras estão rotas e desacreditadas e que já não se tem escolha, perdido que estaria o momento da realização de uma possibilidade, de uma utopia possível, diversa de tudo o que já fora sonhado ou pensado.

Uma visão histórica e antropológica que precisa irromper das fraturas do conhecimento pressupõe uma peremptória recusa de uma realidade que se supõe 


\section{REVISTA REAMEC}

Revista da Rede Amazônica de Edureaçäo

em Ciências e Matemática

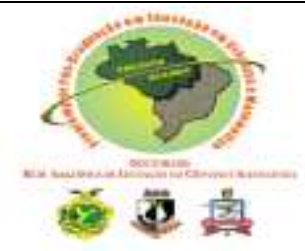

encerrada nas poderosas grades do presente e na recuperação do processo histórico, dos liames entre as etapas pelas quais os homens passaram, colocando em discussão uma ideia de globalização que agora prevalece, interdita o pensamento e a todos aprisiona num presente hegemônico que, conforme Augé (2012, p. 93) já não parece ao homem comum como “[...] oriundo da lenta maturação do passado, já não deixa transparecer os delineamentos de possíveis futuros, mas impõe-se como fato consumado, opressor, cujo surgimento repentino escamoteia o passado e satura a imaginação do futuro".

Salientando esse aspecto comentado por Augé (1997), pode-se observar que agrupamentos são "[...] um mundo porque faz parte do mundo e recapitula todos os traços do mundo atual, não simplesmente microcosmo, mas ponto central, nó de relações, de emissões e de recepções na vasta rede em que o Planeta se constitui hoje”. AUGÉ, 1997, p.176)

É possível reconhecer que o momento histórico de que somos testemunhas involuntárias permite descobrir o espaço que se oferece ao conjunto dos homens no universo fluído e tenso e no modo como tendências opostas à individualidade e à globalidade se manifestam na dimensão local onde, pela força de fundamentos antropológicos, encontram expressão naquelas necessidades sociais opostas e complementares características do esforço que o ser humano desenvolve para se instalar na vida, como bem revela Lefebvre (1978) na obra O Direito à Cidade.

O filósofo francês deixa bastante claro que a ciência que toma a cidade por objeto se vale de métodos, procedimentos e conceitos originários de diversas fontes. Estendendo esse conceito para agrupamentos indígenas, observa-se que com frequência, métodos e conceitos claudicam diante de um objeto em permanente mutação que exige uma nova operação intelectual que ultrapasse a indução e a dedução clássicas. Salienta que há a necessidade da elaboração de modelos de análise que impliquem na “[...]construção de um novo objeto teórico a partir de informações relativas à realidade, assim como a formulação de uma problemática levantada por esta realidade e que tem por premissa um permanente feed-back entre o marco conceitual utilizado e as observações empíricas." (LEFEBVRE, 1978, p. 123-128).

As possibilidades diversas de entendimento de mundo, fazem-se presentes nos espaços indígenas e não indígenas, quando ampliamos a lente sobre os modus vivendi dos mesmos, construído sobre suas necessidades individuais e coletivas. 


\section{REVISTA REAMEC}

Revista da Rede Amazônica de Eduraçäa

em Ciências e Matemática

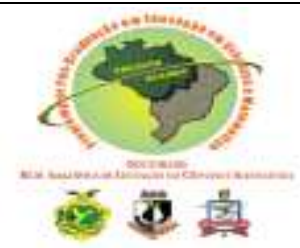

Gaspar (2009) resgata, através de seminários recheados de curiosas histórias, abordando percepções que envolvem aspectos científicos, mitológicos e poéticos de diversas etnias indígenas, diferentes definições sobre o tema marcação do tempo e criação do universo conforme um dos relatos da Etnia Bacairi:

[...] e o vento soprou frio, Tugita para se proteger começou a fazer pinturas em seu corpo, fez um traço na face, uma faixa na fronte, e percebeu no reflexo da água que as cores, à medida que a enfeitava, deixava-a mais bonita. Então passou a pintar seu corpo e sua imagem era percebida, também, pelo sol que fitava-lhe o corpo com sua luz aquecedora. O sol, vislumbrado pela beleza de Tugita, não quis que suas pinturas se desfizesse. Por isso Tugita foi transformada em uma flor que embeleza as margens dos córregos. A beleza da flor é reproduzida nas pinturas faciais e corporais desde o início de tudo e até hoje (GASPAR, 2009, p. 73).

Uma pequena amostra deste cenário ampliado sobre o conceito de tempo, poderá estar associado aos sinais proporcionados pela natureza. Desde a antiguidade, o homem, com seus olhos atentos, sempre foi seduzido a participar das mudanças ocorridas em seu entorno. A acomodação a este estímulo no cérebro humano poderia ser estabelecida pela dinâmica cíclica da natureza: a alternância entre claridade e escuridão para marcar o dia, as fases da lua para marcar semanas ou meses. "Na Amazônia, tudo é feito ou pensado de acordo com as águas, as distâncias, as localizações, o tempo, tudo é contato rio abaixo, rio acima" (BRASIL, 1998, p. 230). Conexões semelhantes entre o saber local (a cognição de que o ciclo da natureza e as caminhadas corriqueiras na floresta de um ponto a outro da floresta é uma constante) e o saber global (entender a leitura de um relógio de pulso, fazer leitura de mapas) gerando um novo saber são notáveis em distintas localidades indígenas.

\section{CONSIDERAÇÕES FINAIS}

A influência do passado é extremamente benéfica quando a lembrança desse passado é tênue e quando a veneração por ele é moderada (TOYNBEE, 1975)

Mais que concluir, reservou-se estas considerações finais para aprofundar algumas reflexões levantadas ao longo do texto. O caminho percorrido até este ponto está, naturalmente, longe, muito longe, de esgotar as problemáticas desafiadoras que a vida urbana na cidade ou da política no universo da cultura ou da política nas questões 


\section{REVISTA REAMEC}

Revista da Rede Amazônica de Edureaçäo

em Ciências e Matemática

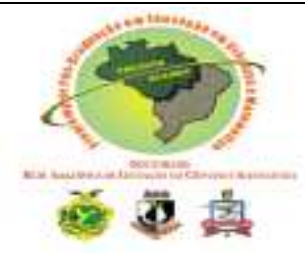

indígenas apresentam, afinal, os males de que padece a sociedade e a urbanidade atingem os indivíduos de todas as classes sociais ainda que de maneira desigual. Os males que afetam o todo - já advertia Emile Durkheim - se propagam às partes que o compõem.

Para dar conta de um fenômeno que, a nosso ver, se insere sob o nome de urbanidade moral, nos marcos da sociedade informacional e da globalização, há que se buscar no mercado comum em que diferentes ramos do conhecimento se cruzam, amalgamando-se uns aos outros, os métodos e conceitos que sejam capazes de dissipar o denso nevoeiro que com frequência embaça o nosso entendimento.

A partir das questões levantadas anteriormente, é possível indicar que alguma forma de regulação do mercado seria necessária para assegurar a superação da desigualdade, entendida como incompatível com a valorização da cidadania e da civilidade, assim como os mecanismos compensatórios e políticas públicas que assegurem a superação da desigualdade que penaliza aqueles que hoje são considerados excluídos ou relegados ã condição de subcidadãos, entre eles os indígenas. O foco do problema está na afirmação identitária a partir de seu reconhecimento e inserção plena na sociedade.

Também não é preciso um grande esforço para reconhecer que a prevalência dos interesses privados e/ou corporativos que prosperam e influem nas câmaras legislativas municipais e outras esferas administrativas, passam por cima do interesse público.

Adorno (1993), um dos expoentes da Escola de Frankfurt vem em nosso socorro quando adverte que "o conhecimento se dá numa rede onde se entrelaçam prejuízos, intuições, inervações, autocorreções, antecipações e exageros, em poucas palavras, na experiência, que é densa, fundada, mas de modo algum transparente em todas as suas partes". (ADORNO, 1993, p.69). E pode-se acrescentar que na cidade, nas suas entranhas mais profundas, se desdobra um drama cujo sentido não se revela senão em parte ao fim de cada ato ou de cada etapa.

O resgate dessa rica experiência que vivemos todos os dias a cada despertar, na vida privada e na vida pública, pressupõe - na e pela experiência - afinar métodos e conceitos num padrão que permita dimensionar a complexidade e a urdidura da vida real tal como ela se expressa no cotidiano tenso das grandes metrópoles ou de aldeias remotas.

É na teia espessa das relações humanas, no modo como elas se deslindam dentro das circunstâncias, nos comportamentos que estimulam, mas também para além deles, 


\section{REVISTA REAMFC}

Revista da Rede Amazônica de Edureaçäo

em Ciências e Matemática.

sempre atentos para que a intimidade e a proximidade que a vida em comunidade assegura não seja um obstáculo para o afloramento da individualidade, da personalidade e das identidades. É também no mundo da cultura tal como se desenvolve e revela em seus múltiplos matizes o sentido da urbanidade ou "[...] uma persona puede ser muy urbana em su modo de pensar y su conduta aunque viva en una aldea [...]" (ANDERSON, 1993, p.15), como a própria condição humana, se enraíza.

\section{REFERÊNCIAS}

ADORNO, Theodor Wiesengrund. Minima Moralia: Reflexões a Partir de Uma Vida Danificada. São Paulo: Ática, 1993.

ANDERSON, Nels. Sociologia de La Comunidad Urbana: una Perspectiva Mundial. México: Fondo de Cultura Economica, 1993.

AUGÉ, Marc. Para onde foi o futuro? Tradução de Eloisa Araújo Ribeiro. Campinas, SP: Papirus, 2012. 121 p. ISBN 978-85-308-0953-9.

AUGÉ, Marc. Por uma antropologia da mobilidade. Tradução de Bruno César Cavalcanti, Rachel Rocha de A. Barros. Revisão de Maria Stela Torres B. Lameiras. Maceió: UNESP: Edufal, 2010. 109 p. ISBN 978-85-393-0059-4.

AUGÉ, Marc. Por uma antropologia dos mundos contemporâneos. Tradução de Clarissa Meirelles, Leneide Duarte. Rio de Janeiro: Bertrand, 1997. 190 p. ISBN 85286-0620-1.

BAUMAN, Zygmunt. A cultura no mundo líquido moderno. Tradução de Carlos Alberto Medeiros. Rio de Janeiro: Jorge Zahar, 2013. 111 p. ISBN 978-85-378-1121-4.

BAUMAN, Zygmunt. Mal-estar da pós-modernidade. Tradução de Mauro Gama, Cláudia Martinelli Gama. Rio de Janeiro: Jorge Zahar, 1998. 276 p. ISBN 85-7110-4646.

BRASIL, Ministério da Educação. Secretaria de Educação Fundamental. Referencial Curricular Nacional para as Escolas Indígenas. Brasília, DF: MEC, 1998.

CIORAN, Emil Mihai. O Livro das Ilusões. Tradução José Thomaz Brum. Rio de Janeiro: Rocco, 2014.

CANCLINI, Néstor García. Imaginários Culturais da Cidade: Conhecimento/ Espetáculo / Desconhecimento. In: COELHO, Teixeira (org.). A Cultura pela Cidade. São Paulo: Iluminuras/Itaú Cultural, 2008. 


\section{REVISTA REAMEC}

Revista da Rede Amazônica de Edureaçäo

em Ciências e Matemática

GASPAR, Waldir José. Se ninguém me perguntar eu sei, mas quando me perguntam... . In: JANUÁRIO, Elias e SELLERI SILVA, Fernando (org.). Caderno de Educação Escolar Indígena. v.7, n.1.p.71-87, Barra do Bugres: UNEMAT, 2009. 135 p. ISSN 16770277.

LEFEBVRE, Henri. EI Derecho a la ciudad. 4. ed. Barcelona: Península, 1978. 169 p. ISBN 8429709169.

LIPOVETSKY, Gilles; SERROY, Jean. A cultura-mundo: resposta a uma sociedade desorientada. Tradução de Maria Lúcia Machado. São Paulo: Companhia das Letras, 2011. 208 p. ISBN 978-85-359-1797-0.

PIKETTY, Thomas. A economia da desigualdade. Tradução de André Telles. Rio de Janeiro: Intrinseca, 2015. 142 p. ISBN 978-85-8057-648-1.

RIBEIRO, Darcy. O povo brasileiro: a formação e o sentido do Brasil. 3. ed. São Paulo: Global, 2015. 358 p. ISBN 978-85-260-2225-6.

SAFATLE, Vladimir. O Circuito dos Afetos. Corpos políticos, desamparo e o fim do indivíduo. São Paulo: Cosacnaify, 2015. ISBN 9788540509603

SENNETT, Richard. Declínio do homem público: as tiranias da intimidade. Tradução de Lygia Araújo Watanabe. São Paulo: Cia. das Letras, 1988. 447 p. ISBN 8585095814.

TOYNBEE, Arnold Joseph. O Desafio de Nosso Tempo. 2. ed. Rio de Janeiro: Zahar, 1975.

WEBER, Max. Ensaios de Sociologia. Obra prefaciada por GERTH, Hans H.; MILLS, Charles Wright (org.). Tradução de Waltensir Dutra. 3. ed. Rio de Janeiro: Zahar, 1974. $530 \mathrm{p}$.

Submetido em: 02 de outubro de 2019.

Aprovado em: 09 de dezembro de 2019. 